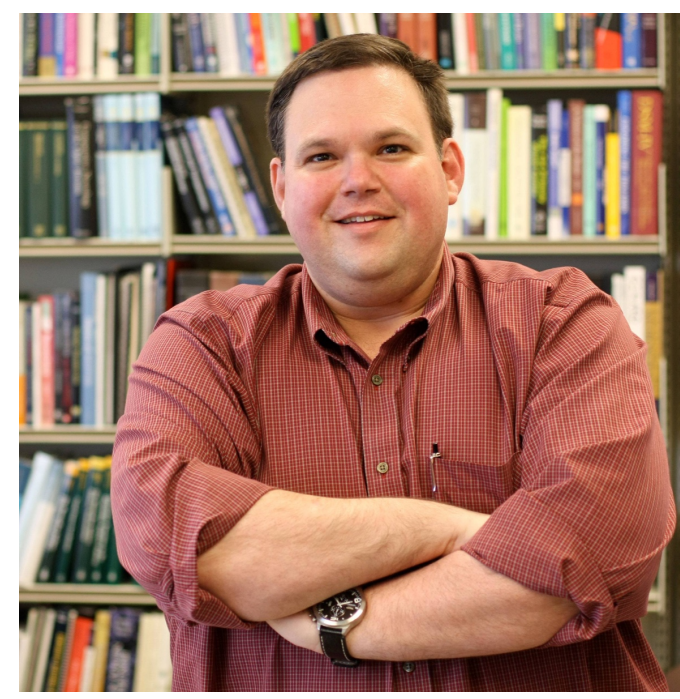

\title{
Western Faculty Profile: Dr. Stephen Lomber
}

\author{
Shengjie Ying ${ }^{1}$ \\ ${ }^{1}$ Faculty of Science, Western University, London, Canada \\ No conflicts of interest declared
}

\section{Background}

I grew up in New York, near the Thousand Island bridge, so literally just over the border. I did my undergraduate work at the University of Rochester, and when I started as an undergrad I began as a psychology major. When I took social psychology during my first year, I thought it was one the of the most awful courses I had ever taken because it didn't have anything to do with the brain as I had thought about it. I really wanted to understand why people behave a particular way and at that time it just seemed like theories and ideas, we weren't getting down to any sort of biology. So I went home the summer after my first year, and through a friend of a friend of a friend, found a volunteer position in a neuroscience lab that was working on how the brain controls eye movements in monkeys, and I thought this was the greatest thing I have ever done. We were actually doing biology on behaviour. So after the summer, when I went back to school, I found a lab at Rochester that did a similar type of eye movement research in monkeys. From the fall of my second year through my entire undergrad, I worked at this lab which I just thought was spectacular. At that point, I thought I would rather be in the lab than go to class. As a consequence of that I actually changed my major from psychology to neuroscience. At that time, [the University of Rochester] was one of the few schools in North America that had a neuroscience degree for undergrads.

My undergraduate experience was phenomenal, but when I got to the end of my undergrad I wondered what did I want to do next? I wanted to continue to work in vision, but not in monkeys. I ended up going to Boston and working on the feline visual system and did my Master's and $\mathrm{PhD}$ at Boston University. While I was there I became really interested in developmental issues and I learned a lot about neurophysiology and neuroanatomy. Boston was an amazing place to a student. The city is very young and there are all sorts of things to do and see. Around 2000, I got very serious about looking for jobs. I was starting to get interested in hearing rather than vision and I became very interested in how the brain deals with the activation of a naïve system. What I mean by that is if you have someone who is blind or someone who is deaf and you could activate that system with some sort of prosthetic device. An example with hearing would be a cochlear implant. If that auditory pathway hasn't been active for some time, how does the brain deal with being turned back on again? Since there isn't really a decent retinal prosthetic, if I wanted to answer that question I had to move from vision into hearing. I wanted to move to a university where hearing was a big deal, so I went to the University of Texas in Dallas. After a few years, we invited Mel Goodale from Western for a talk and Mel asked "Why aren't you at Western?". So I was considered for a position here and they made me an offer I couldn't refuse. My wife and I moved here in 2006 and I started at UWO as an associate professor. I think it's just been great at Western. Absolutely wonderful.

\section{What's your favourite part of being at Western?}

It's really a great place to grow a research program. There are fantastic students, both graduate and undergraduate. I think during the ten plus years I've been here, the focus on research has only expanded, particularly in science and neuroscience. There are very supportive Deans and department chairs. It's a combination of things: you've got fantastic people, fantastic equipment and resources.

\section{What do you love so much about teaching?}

All my teaching is with undergrads and I find that there's an enthusiasm level with undergrads that you don't find with graduate students. Graduate students tend to be more focused, whereas undergraduates are more like "tell me about everything". They just want to sponge it all up. So there's an enthusiasm level there that you don't see with more senior students. It's kind of thrilling, but it can also be very intimidating when you stand in front of 700 students, like when I'm teaching physiology 2130 . When I teach neuro 2000 , there may be 50 or 60 students. That's really great because you get to have interactions there that you can't have in a really big class. I think I prefer teaching to a smaller 
setting because you have that interaction so if somebody doesn't understand you can immediately take them through it and go through what they need to know, whereas in a bigger classroom occasionally you can take some questions but only from a very small handful of students. I think it's difficult at the end of the class to know if everyone understood everything, whereas if I have a class of just 50 students, when you're done you feel like everybody understood it and really knows what's going on. I think working with small groups of undergrads is most satisfying.

\section{How would you compare how teaching is done now and what is was like when you were an undergrad?}

I think when I was an undergrad, there was more of a feeling that you were on your own. You were given a syllabus and a bunch of things to learn and you were set off to learn them. Now there's more of an emphasis on directly communicating what needs to be learned. When I was an undergrad and asked "what's going to be on the exam?", the answer was "everything in the book". Now it's more defined in terms of learning objects instead of just go learn it on your own, but that does have its plusses and minuses.

\section{What do you think are those plusses and minuses with those different approaches?}

I think now it's easier to understand what somebody has actually learned. There used to be a lot more variability in terms of how much somebody actually got out of a class. The student may have done a lot of work but may not have done very well on the exam since things were so free form. If there's anything that I miss it's going to the library. Even now I miss that because that used a whole learning exercise about going to the library, finding the journals, sitting in the aisle, and just reading them right there. It was harder to get information, but when you got it you sponged it up a lot more. It was the thrill of the hunt. The other thing I really miss is if I was looking for a particular paper, it was easier to make accidental discoveries. There used to be a lot more of just bumping into papers and saying "Wow that's a really neat study".

\section{What are some of your hobbies?}

My wife and I love to travel. The next thing on our list is going to Antarctica. We've been to every continent but Antarctica and I think that would be very cool. We also have two fantastic dogs that I love spending time with. I don't know if I really have any hobbies at the moment, that kind of comes and goes. Historically, I've been involved in scouting - both at a national and international level. Again that's working with young people, which I always enjoy. But I don't collect stamps or anything like that.

What I find really challenging is imagining what it would be like to have a job that I didn't love. I really have a hard time imagining what that would be like because I'm so excited to come in every morning. I can't imagine doing a job I perceived as a grind or just working to put in hours. For me it's just how much can I get done today, what sort of extraordinary things are going to happen in the lab today. I can't imagine doing anything else because it's so incredibly fulfilling. It just stimulates you on so many levels. I also can't imagine why I would retire. I just love this so much.

\section{Earlier, you mentioned how when you got into that neuroscience lab and switched out of psychology, that was a moment that really clicked for you. What would you recommend for students who haven't had that moment yet, and are still not sure what they are truly interested in?}

Get out of the classroom! You can get general ideas in the classroom, but if you really want to find your thing, then you need to get involved in a lab, or in more than one lab. I think what really flipped the switch for me was, as an undergrad I thought I was doing something very interesting, but even more, it was that I was given responsibility. I think that if people are given the opportunity to take charge and make things happen, and actually have expectations put on them, then people rise to the occasion and will do really well. Whereas if no one ever expects anything of you then you don't really make an investment. To me it was all about someone giving you a chance to show what you can do and I'm not sure if people get that same kind of satisfaction level out of "I got a 93\%". Usually when I'm teaching second year students, I'Il ask them why aren't you in a lab yet? Why aren't you going around, seeing the type of stuff you like to do because there's all sorts of spectacular stuff going on, but it's in labs, not in the classroom. Generally, in the classroom setting, you're being told the way things are, whereas in the lab you're finding out the things we don't know, and how are we going to figure these things out. When you read things in a textbook it feels like we have everything all figured out, and you don't know that there's a thousand other questions that we're trying to understand. For any discovery that occurs, if it's really interesting, it should actually launch a whole bunch of other questions. So if somebody really wants to get excited then they really need to go into a lab. Even if someone wants to go into clinical work, there's plenty of exploratory clinical work they can do as well. People are always looking for enthusiastic students in their lab, so take advantage of it.

\section{To Learn more on Dr. Lomber's lab and research, please visit his website at:}

http://www.schulich.uwo.ca/physpharm/people/bios/faculty/lombe r_stephen.html

or

http://cerebralsystems.ca/ 